\title{
Problems encountered in studying the nutrition of the cat (Felis catus Linn.)
}

\author{
By Patricia P. Scott, Physiology Department, Royal Free Hospital School of \\ Medicine, 8 Hunter Street, London, W.C.x
}

Though every schoolboy knows how to feed mice it is not easy to devise adequate standardized diets for colonies of mice and rats maintained in the laboratory (Bruce \& Parkes, I 949). Similarly, every housewife knows that cats thrive on plate scraps occasionally supplemented by fish or meat, but the translation of this regime into a standard stock diet for cats in the laboratory raises a surprising number of difficulties. Attempts to define the nutritional requirements of domestic cats have been frustrated by inadequate supplies of kittens of similar age, genetic constitution and environmental background; by lack of standard growth curves; and by a relative lack of data relating nutritional status to reproductive efficiency. To overcome these difficulties I started a colony of cats in $195^{\circ}$, which now consists of thirty female and three male cats, sufficient to produce adequate groups of half-sib kittens permitting the design of experiments susceptible of statistical analysis. Moreover, since cats continue reproducing over a number of years, successive groups of full-sib kittens have become available for serial experiments on single problems.

\section{Standard data}

Growth. Live-weight gains of kittens were first measured by Abderhalden (1898) who found that litters doubled their birth weight in 9 days, and could equal their mother in weight by the end of the lactation period. Abderhalden correlated the rapid growth of kittens with the high solid content of cat's milk; according to Abderhalden (1898) and to Davies (1939) cat's milk contains: protein $7 \cdot 0-7 \cdot 3 \%$, fat $4 \cdot 4-4 \cdot 75 \%$, lactose $4 \cdot 8 \%$ and ash $0 \cdot 58-1 \cdot 02 \%$ by weight. Young kittens are continuous feeders, gaining steadily from birth, a fact observed by Latimer \& Ibsen (I932) who followed the weight gains of twelve kittens for 13 weeks, and Hall \& Pierce (I934) who studied the growth of seventy healthy kittens, born in the laboratory and reared to 7 weeks (the lactation period) under standard conditions. da Silva $(195 \circ b)$ gave figures for the weight gained by small numbers of kittens from 2 to I 5 months of age collected from domestic homes and reared in the laboratory on a standardized ration. We measured the weight gains of healthy kittens born in our colony and reared on the stock diet described below (Dickinson \& Scott, 1956a). Weighings to the nearest $2 \mathrm{~g}$ were carried out three times weekly, between meals, of which one was offered at I I a.m., the other at 4 p.m.; unfed kittens were found to weigh about $5 \%$ less than those that had eaten recently. Growth curves (Fig. I) for male and female kittens were obtained with a minimum of fifteen kittens of one sex for any mean plotted (maximum forty-eight). Since, over considerable periods, the rate of gain appeared remarkably steady, it is convenient to calculate the daily 


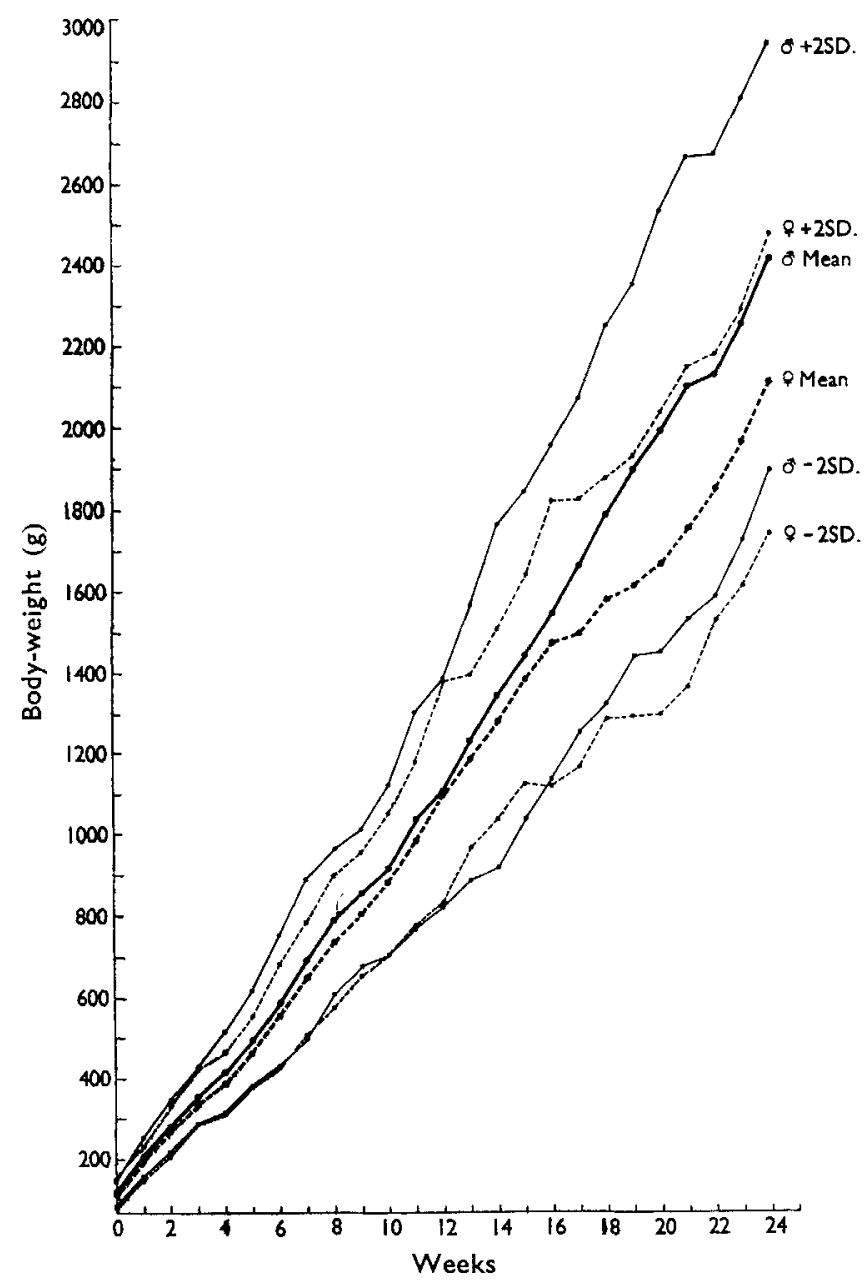

Fig. I. Mean growth curves, with twice the standard deviation, for healthy male and female kittens from birth to 24 weeks of age. Minimum number for any plot is 15 , maximum 48 . (Dickinson $\&$ Scott, I956a).

weight gains of the animals over these periods (Table $\mathrm{I}$ ), thus providing a basis for comparison between growth on stock and experimental diets, no matter what the duration of the experimental period. Between birth and 12 weeks of age, weight was more important than sex in determining the rate of gain, that is the largest animals grew fastest. A marked difference between the sexes became apparent between the I 2 th and 20 th weeks, males gaining weight more rapidly than before, but females showing a decline in the rate of gain. Other (unpublished) data suggest that this difference may have been due to activity of the gonads in this period. Further changes in the rate of gain were apparent in both sexes after the 2oth week, medium and large males showing a reduced gain, but small males still exhibited maximal growth. In the females the rate increased for animals of all sizes and was 
Table I. Daily weight gains of healthy kittens calculated from the data of Dickinson \& Scott (1956a)

\begin{tabular}{|c|c|c|c|c|}
\hline Age group & $\begin{array}{l}\text { No. and } \\
\text { sex }\end{array}$ & $\begin{array}{c}\text { Mean rate } \\
\text { of gain } \\
\text { (g) }\end{array}$ & $\begin{array}{l}\text { Rate of gain } \\
\text { of largest } \\
\text { kitten } \\
\text { (g) }\end{array}$ & $\begin{array}{l}\text { Rate of gain } \\
\text { of smallest } \\
\text { kitten } \\
\text { (g) }\end{array}$ \\
\hline Newborn-I 2th week & $\begin{array}{l}30 \mathrm{M} \\
20 \mathrm{~F}\end{array}$ & I I 8 & $14 \cdot 6$ & $9 \cdot 4$ \\
\hline $\begin{array}{l}\text { I 2th-2oth week } \\
\text { 2oth-24th week }\end{array}$ & $\begin{array}{l}24 \mathrm{M} \\
18 \mathrm{~F} \\
16 \mathrm{M} \\
15 \mathrm{~F}\end{array}$ & $\begin{array}{l}16.0 \\
10.0 \\
13.2 \\
16.0\end{array}$ & $\begin{array}{l}23.8 \\
10.6 \\
11.6 \\
20.0\end{array}$ & $\begin{array}{r}12.0 \\
9 \cdot 0 \\
18.0 \\
16.0\end{array}$ \\
\hline \multicolumn{5}{|c|}{$F=$ females, $M=$ males } \\
\hline
\end{tabular}

nearly equal to that of the males in the preceding period. Thus, in evaluating results of nutritional experiments based on weight gain, it is necessary to take into account the age and sex of the kittens.

Effects of disease. Cats, especially just after weaning or when pregnant, are highly susceptible to endemic conjunctivitis, coryza, pneumonitis and various forms of enteritis (Scott, 1952, I957). Although by causing anorexia and weight loss these diseases obscure the results of dietary experiments, it has become increasingly apparent that resistance to them is associated with an adequate diet.

Reproduction. Standards for reproductive efficiency can only be assessed over considerable periods of time. The mean number of young per litter in our colony was $3.3 \pm 0.24$ in $1951,4.4 \pm 0.31$ in $1952,3.7 \pm 0.23$ in $1953,4.0 \pm 0.22$ in 1954 and $4.1 \pm 0.21$ in 1955 . Two litters are the least that should be expected in any one year (Scott \& Lloyd-Jacob, 1955; Dickinson \& Scott, 1956a).

\section{Nutritional requirements}

Proteins. Proteins are concentrated in cat's milk (casein $3.71 \%$, lactalbumin $3.29 \%$ in whole milk), and weaned kittens have a high protein requirement. da Silva (1957) found that $22 \%$ casein in the diet was insufficient to maintain growth, although kittens recovered their weight when returned from $22 \%$ to $33 \%$ casein. Using a mixed diet in which liver, fish and lights formed the principal sources of protein, we found that growth of kittens was only satisfactory when the protein fraction $(\mathrm{N} \times 6.25)$ exceeded $30 \%$ of the dry weight of the diet (Dickinson \& Scott, I955, 1956b). It is not clear whether this high level, compared with that adequate for other species, represents a high total nitrogen requirement, or a demand for particular amino-acids or for other protein-associated factors.

Kittens grew well, and cats reproduced 'satisfactorily' when raw, lean meat or heart muscle was given as source of protein (Hall \& Pierce, 1934; Pottenger \& Simonsen, 1939; Pottenger, 1946, Robinson, 1947; da Silva, 1957). But Pottenger (1946) found that heat treatment of meat, by cooking (no details of time or temperature given), resulted in a reduction in the number of offspring, increased stillbirths and maternal deaths during delivery. Viable offspring showed unsatisfactory growth 
with poor muscle tone and abnormal bone and tooth development; third generation kittens on the cooked diet survived only 2 months (Pottenger \& Simonsen, 1939). Robinson (1947) found that the growth rate of weaned kittens was reduced and the reproductive performance of adult females was poor, kittens dying within a few days of birth, when cats were placed on a canned or dehydrated meat--cereal diet. Yet these diets supported 'good to excellent' reproduction in rats and dogs, and apparently maintained adult cats in health. Robinson tried supplementing the processed diets without improvement in reproduction. It is possible that failure to digest the heat-treated protein may have brought about this 'cooked meat syndrome', which has features in common with the effects of diets, dried at $140^{\circ}$ and above, on rats (Frazier, Cannon \& Hughes, r953; Harms \& Scott, r956). Evidence from our laboratory suggests that the ability of young kittens to utilize various foods is inferior to that of older cats, so that it may be possible to maintain adult cats on diets that will not support growth or pregnancy.

Fat. Mackay (I92I) by comparing growth on diets containing either cream or olive oil showed that 'deficiency of animal fat' depressed and finally inhibited growth of kittens. Mackay's olive-oil diet was undoubtedly deficient in vitamin A as well as 'animal fat'. Feeding purified diets which included cod-liver oil, da Silva (I957) found that either $25 \%$ butter, or $12.5 \%$ lard with $12.5 \%$ cottonseed oil, gave about the same results. We observed that the addition of fat (margarine) markedly improved the acceptance of a purified diet. The high calorie value of fat may be important in maintaining rapid growth, besides fat acting as a vehicle for fat-soluble vitamins. The requirements of cats for fatty acids are unknown.

Carbohydrate. In our experience cooked potato and biscuit meal are highly acceptable and are well digested by cats and kittens. These foods reduce the cost of a stock diet, but there is no evidence that carbohydrates are essential for cats.

Vitamins. Much of the literature on dietary deficiencies refers to treatment given for conditions met with in veterinary practice. Heath, MacQueen \& Spies (r940) observed a syndrome characterized by oral inflammation and ulceration which responded to two doses of 80-100 $\mathrm{mg}$ nicotinic acid, and which they therefore called 'feline pellagra'. Cordy \& Stillinger (1953) described cases of steatitis (yellow fat disease) in kittens that had been given a commercial canned cat food consisting of fish with $10 \%$ cereal. Cordy (1954) carried out experiments which showed that this condition was probably due to deficiency of $\alpha$-tocopherol, although his experiments were not well controlled. Cats fed on raw fish (carp or herring), on the other hand, showed loss of weight, followed by ataxia, convulsions, and death in 23-40 days. Smith \& Proutt (I944) found that such signs were prevented by injections of thiamine, and that they were caused by an antithiamine present in uncooked fish. Although cod-liver oil is included in many diets for cats no information appears to exist as to the precise levels of fat-soluble vitamins required at any age.

The B-vitamins requirements of weanling kittens have been studied in some detail by da Silva (1957), da Silva, Fried \& de Angelis (1952), and da Silva, de Angelis, Portes \& Guerios (1955), who used a purified diet consisting of vitaminfree casein 33 , purified gelatine 2 , sucrose 35 , butter 25 (or cottonseed oil 12.5 and 
lard 12.5\%) and salt mixture IV (Phillips \& Hart, 1935) $5 \%$ with appropriate vitamin supplements. The signs of thiamine deficiency were loss of weight and ataxia, recovery occurring on $20 \mu \mathrm{g}$ daily; riboflavin deficiency gave weight loss and diarrhoea, curable by $20 \mu \mathrm{g}$ daily; pyridoxine deficiency gave weight loss, microcytic anaemia, high plasma iron, kidney lesions and epileptic fits curable by I $\mathrm{mg}$ daily; pantothenic-acid deficiency gave weight loss curable by I mg daily; folic-acid deficiency, only obtained on the purified diet with sulpha drugs, gave weight loss, anaemia and leucopenia, curable by $0.2 \mathrm{mg}$ daily. Nicotinic-acid deficiency gave weight loss, diarrhoea and death preventable by an optimum of $\mathrm{I}$ o $\mathrm{mg}$ daily. It was also observed that nicotinic acid could not be replaced by tryptophan in the cat. Ascorbic acid is not required (da Silva, I957).

Mineral salts. The requirements of the cat for mineral salts are even less well understood than those for vitamins. da Silva (1957) included a commonly used salt mixture at the $5 \%$ level in his purified diet, and Dickinson $\&$ Scott $(1954,1956 c)$ obtained excellent growth on a fish-liver-cereal diet in which ash formed $9.1 \%$ of the dry weight. When additional bone salts were added to this diet no improvement was observed in bone density judged by radiographic examination, neither were pathological changes observed in the urinary tracts of male or female kittens receiving $30.1 \%$ (dry-weight basis) bone salts in the diet, although some workers have stated that high-mineral diets induce urethral calculi in cats (Morris, 1953).

Stock diets. Stock diets used by workers in America and Britain have been reviewed by Cumming \& Cumming (1953) and Scott (1957). In devising stock diets the following points are important: the ingredients selected must be of good quality and adequate supplies obtainable throughout the year; they should require a minimum of handling and preparation, and be easily stored; the diet must be nutritionally adequate and acceptable to cats and kittens; finally it must be reasonable in cost. It is obvious that no diet, up to the present, fulfils all these requirements, most fresh ingredients require considerable preparation, and dependence on canned diets may lead to deficiencies. In fact, owing to our present ignorance, the only method of ensuring nutritional adequacy, is to feed a varied diet, high in animal protein. Liquid milk and meat are to be avoided owing to their cost unless especially cheap supplies are available. The stock diet given to our colony is based on cooked potatoes, with fish, liver or lights as sources of protein (protein $(N \times 6.25)$ exceeds $60 \%$ of the dry weight) with the addition of dried-grass powder and yeast. This diet is fed as a main meal, and a subsidiary meal of milk powder and fortified cooked meal (Farex, Glaxo Laboratories Ltd) is also given daily. The preparation of and the results obtained on this diet are described by Cornelius (1952) and Dickinson \& Scott (1956a). Saunders (1953) gave the weight gains and food consumption of kittens receiving a diet consisting of casein, rat cubes (powdered diet $4 \mathrm{I}$ of Bruce \& Parkes, r949) cooked potatoes and choline chloride on which the animals gained satisfactorily. Many authors have pointed out that consistency is an important factor in the acceptance of a diet by cats. Moreover, on changing the diet, $1-3$ days of adjustment are often needed before normal weight gains are resumed. 
Quantity of food. In our colony the stock diet (Dickinson \& Scott, I956a) was fed at the daily rate of $200 \mathrm{~g}$ (wet weight) main meal and $100 \mathrm{~g}$ secondary meal, per adult cat. It provided $140-150 \mathrm{Cal} / \mathrm{kg}$ cat $/$ day. Since these animals were actively reproducing it is probable that resting adults could be maintained on smaller amounts. Food consumption of kittens varied from about $70 \mathrm{~g} /$ day at weaning to I $40 \mathrm{~g}$ by 16 weeks.

Antibiotics. The addition of procaine penicillin, penicillin G, and aureomycin (chlortetracycline) at the level of $30 \mathrm{i}$.u. $/ \mathrm{kg}$ wet diet significantly increased the weight gain of kittens compared with controls, resulted in an increased efficiency of conversion $(7.80 \mathrm{~g}$ against $5.95 \mathrm{~g}$ weight gain/100 Cal.) and gave greater resistance to endemic disease (Dickinson \& Scott, I955).

\section{Summary}

Lack of specific data on growth rate and reproductive efficiency, together with limited information concerning nutritional requirements has hindered the development of satisfactory stock diets for cats. High-protein diets are essential for growth and reproduction, and some information is available on the requirements for members of the B-vitamin complex for growth. Endemic disease may be troublesome in attempts to carry out nutritional investigations on cats. Because of its convenient size, its great importance in physiological and pharmacological research, and the interesting metabolic differences it has shown from the rat, the cat merits further consideration as a laboratory animal.

The author wishes to express her grateful thanks to all those whose encouragement and assistance made the cat colony a reality, and to the Royal Society, Medical Research Council and University of London for generous financial aid.

\section{REFERENCES}

Abderhalden, E. (1898). Hoppe-Seyl. Z. 26, 487 .

Bruce, H. M. \& Parkes, A. S. (1949). \%. Hyg., Camb., 47, 202.

Cumming, C. N. W. \& Cumming, E. L. W. (1953). Carworth Farms Quarterly Letter, no. 31.

Cordy, D. R. (1954). Cornell Vet. 44, 310.

Cordy, D. R. \& Stillinger, C. J. (1953). N. Amer. Vet. 34, 714.

Cornelius, O. (1952). F. Anim. Tech. Ass. 3, 4I.

Davies, W. L. (1939). The Chemistry of Milk, and ed. p. 7. London: Chapman \& Hall.

da Silva, A. C. (I950a). Acta physiol. lat.-amer. I, 20.

da Silva, A. C. ( $950 b$ ). Acta physiol. lat.-amer. 1, 25.

da Silva, A. C. (1957) In The U.F.A.W. Handbook on the Care and Management of Laboratory Animals, and ed., chapter 46. [A. N. Worden and W. Lane-Petter, editors.] Tunbridge Wells: Courier Publishing Co. (In the Press.)

da Silva, A. C., de Angelis, R. C., Pontes, M. A. \& Guérios, M. F. M. (1955). F. Nutr. 56, I 99.

da Silva, A. C., Fried, R. \& de Angelis, E. C. (1952). F. Nutr. 46, 399.

Dickinson, C. D. \& Scott, P. P. (1954). Brit. F. Nutr. 8, 380.

Dickinson, C. D. \& Scott, P. P. (1955). F. Physiol. 129, 78P.

Dickinson, C. D. \& Scott, P. P. (I956a). Brit. F. Nutr. 1o, 304.

Dickinson, C. D. \& Scott, P. P. (I956b). Brit. F. Nutr. ro, 3 I 1 .

Dickinson, C. D. \& Scott, P. P. (1956c). Vet. Rec. 68, 858 .

Frazier, L. E., Cannon, P. R. \& Hughes, R. H. (1953). Fond Res. 18, 9r.

Hall, V. E. \& Pierce, G. N. (I934). Anat. Rec. 6o, II I.

Harms, A. J. \& Scott. P. P. (1956). F. Sci. Fd Agric. 7, 477. 
Heath, M. K., MacQueen, J. W. \& Spies, T. D. (1940). Science, 92, 5 I4.

Latimer, H. B. \& Ibsen, H. L. (I932). Anat. Rec, 52, I.

Mackay, H. M. M. (1921). Biochem. F. 15, 19.

Morris, M. L. (1953). Vet. Med. 48, 45 I.

Phillips, P. H. \& Hart, H. B. (I935). F. biol. Chem. rog, 657.

Pottenger, F. M. (1946). Amer. $\mathscr{F}$. Orthodont. 32, 467.

Pottenger, F. M. \& Simonsen, D. G. (1939). F. Lab. Clin. Med. 25, 238.

Robinson, H. E. (1947). In Appraisal of Human Dietaries by Animal Experiment, p. 4I. [R. R. Williams, editor.] New York: Williams Waterman Foundation.

Saunders, J. A. (1953). F. Physiol. 121, 12P.

Scott, P. P. (1952). F. Physiol. x18, 35P.

Scott, P. P. (1957). In UFAW Handbook on the Care and Management of Laboratory Animals, 2nd ed., chapter 46. [A. N. Worden and W. Lane-Petter, editors.] Tunbridge Wells: Courier Publishing Co. (In the Press.)

Scott, P. P. \& Lloyd-Jacob, M. A. (1955). Stud. Fertil. 7, 123.

Smith, D. C. \& Proutt, L. M. (1944). Proc. Soc. exp. Biol., N.Y., 56, I.

\section{The role of an adequate diet in the production of healthy guinea-pigs}

\section{By J. Stuart Paterson, Ministry of Supply Establishment, Allington Farm, Porton Down, Salisbury, Wilts}

An adequate diet for a laboratory guinea-pig does not suddenly become a matter of importance because that animal has just been included in an experimental group: it is important that the animal should have received proper nourishment in its earlier life and it was equally important that its mother had been properly fed. If we make an exception for certain nutritional studies which involve the manipulation of the diet of the pregnant animal then $I$ think one must agree that the proper nutrition of the expectant and lactating mother is as important as the proper feeding of the growing young. The production of healthy guinea-pigs, as with other species, depends upon two primary considerations, adequate diet and suitable environment and, of these, I consider diet to be the more important. Quite reasonable guineapigs may be produced under poor environmental conditions but I doubt if firstclass animals are ever produced where the diet is faulty.

At a symposium such as this, I feel a little diffident in drawing attention to the paucity of information on the exact nutritional requirements of the guinea-pig, but, nevertheless, I think we know sufficient to provide an adequate diet for them. The guinea-pig is a vegetarian by nature and will thrive on a wide variety of diets provided care is taken to include adequate amounts of fresh vegetable food to provide the animal with a sufficient amount of vitamins $\mathrm{C}$ and $\mathrm{E}$, and sufficient hay to provide an, as yet, unidentified factor. A guinea-pig will consume quite prodigious quantities of these two basic feeding-stuffs-even up to a third or a half of its own body-weight of vegetables daily particularly if water is not readily available. Guineapig fanciers have long realized that it was necessary to supplement this simple diet with some form of concentrate if regular breeding and a reasonable survival rate of youngsters was to be achieved. For many decades, fanciers and the laboratories breeding guinea-pigs employed as a concentrate a mixture consisting of one part 